\title{
Percepções maternas sobre a alimentação de pré-escolares: subsídios para uma atuação em creches e pré-escolas
}

\author{
MATERNAL PERCEPTIONS ON THE NUTRITION OF PRE-SCHOOL CHILDREN: \\ SUBSIDIES FOR PREVENTIVE ACTIONS IN DAY CARE CENTERS AND PRE-SCHOOLS
}

\author{
PERCEPCIONES MATERNAS SOBRE LA ALIMENTACIÓN DE PRE-ESCOLARES: \\ SUBSÍDIOS PARA UNAACTUACIÓN PREVENTIVA EN GUARDERÍAS Y JARDINES
}

\section{Silvia Sanches Marins ${ }^{1}$, Magda Andrade Rezende ${ }^{2}$}

1 Enfermeira. Mestranda em Enfermagem Pediátrica da Escola de Enfermagem da Universidade de São Paulo (EEUSP). silviasm@usp.br

2 Orientadora da pesquisa. Docente da área de saúde da criança da EEUSP.

Coordenadora do grupo de pesquisas "Saúde em Creches e Saúde da Criança" (Diretório de Grupos de Pesquisas do CNPq - versão 5.0) marezend@yahoo.com.br
(a)A fase chamada préescolar pelos teoristas em desenvolvimento está baseada, tanto na idade cronológica, de 3 a 6 anos de idade, quanto nas aquisições psicossociais, cognitivas, espirituais e sociais.
Justificativa: a alimentação da criança durante a fase pré-escolar (a) constitui-se um processo complexo devido aos fatores relacionados ao desenvolvimento próprio desta fase e os referentes às condições ambientais. Na literatura, podemos observar algumas estratégias para auxiliar a criança e seus cuidadores durante as refeições nesta fase do desenvolvimento infantil, porém na prática, observamos que ainda é elevado o número de adultos com dificuldades e por vezes até comportamentos errôneos durante as refeições. Visto que os hábitos alimentares adquiridos na infância tendem a se solidificar na vida adulta, é de suma importância atitudes assertivas durante esta fase do desenvolvimento infantil, estimulando assim, precocemente, a formação de hábitos saudáveis. Assim, torna-se importante que o enfermeiro esteja a par das dificuldades e atitudes dos adultos durante as refeições, para que possa atuar de maneira efetiva, promovendo desta forma a saúde destas crianças a médio e longo prazo. Visto que as creches e pré-escolas concentram um grande número de crianças, de educadores, e indiretamente de pais, constituem-se espaços adequados para capacitação de adultos acerca dos aspectos relativos à alimentação, como também para promoção da saúde das crianças. Objetivo: conhecer as percepções de mães sobre a alimentação de seus filhos de três a seis anos que freqüentam instituições de educação infantil. Metodologia: da pesquisa qualitativa, que permite conhecer, interpretar e compreender particular e profundamente o fenômeno segundo a ótica dos sujeitos. A população materna será caracterizada quanto a: idade, escolaridade, formação/profissão; número de fillhos; idade dos filhos, e número de filhos que freqüentaram a instituição. Análise dos dados: os dados serão coletados por meio de entrevistas que serão gravadas, transcritas e submetidas a análise de conteúdo segundo metodologia proposta por Bardin. A técnica de análise de conteúdo escolhida será a técnica de análise temática, que permite a descoberta do que está por trás dos conteúdos manifestos. Cuidados éticos: o projeto já foi analisado e aprovado pelo Comitê de Ética da Escola de Enfermagem da USP. Cronograma: a previsão do término é janeiro de 2005.

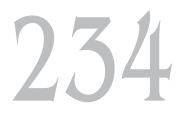

